\title{
THE BEHAVIOR OF SYNCHRONOUS MOTORS DURING STARTING
}

BY

F. D. NEWBURY

Presented under the auspices of the

\section{Industrial Power Committee}

JOHN M. HIPPLE, Chairman, W. E. \& M. Company, East Pittsburgh, Pa.

H. B. EMERSON, Methuen, Mass.

R. S. FEICHT, Pittsburgh, Pa.

E. FRIEDLANDER, Braddock, Pa.

E. H. KIFER, Madison, Wis.

C. D. KNIGHT, Schenectady, N. Y.
J. C. LINCOLN, Cleveland, Ohio.

R. S. MASSON, Los Angeles, Cal. W. H. POWELL, Milwaukee, Wis. BARTON R. SHOVER, Youngstown, Ohio. R. H. TILlmaN, Baltimore, Md. 


\title{
BEHAVIOR OF SYNCHRONOUS MOTORS DURING STARTING
}

\author{
BY F. D. NEWBURY
}

\section{Abstract of Paper}

The paper presents experimental data mainly in the form of oscillograms bearing on the subject of the paper.

The oscillograms show very completely the effect on field current and armature current of a large number of combinations of starting conditions.

From the oscillograms and curves, the following practical operating results are deduced:

1. That the effect of the closed field circuit on initial starting torque is negligible if low resistance damper windings of good design are used.

2. That with open field circuit during starting dangerous voltages are induced in the field winding.

3. That for all ordinary applications, at least, motors should be started with closed field circuit.

4. That successively larger loads can be pulled into synchronism if synchronism is attained:

(a) On the starting voltage without excitation;

(b) On the starting voltage with excitation; and

(c) On line voltage with excitation.

5. That for moderate loads the minimum starting current is obtained by considerably over-exciting the motor before changing to line voltage.

6. That for large loads during starting and synchronizing, minimum starting current is obtained by under-exciting the motor before changing to line voltage.

7. Still further reduction in starting current is obtained by the use of reactance between the change from starting to line voltage, in which case excitation is delayed until the motor is in, or very near, synchronism. 
A paper to be presented at the 30th Annual Convention of the American Institule of Electrical Engineers, June 25, 1913.

Copyright, 1913. By A. I. E. E.

(Subject to final revision for the Transactions.)

THE BEHAVIOR OF SYNCHRONOUS MOTORS DURING STARTING

BY F. D. NEWBURY

Considerable information has been presented before the Institute and elsewhere concerning the performance of self-starting synchronous motors, but this has dealt mainly with the mathematics of initial starting torque and current and the performance under a few of the simpler conditions of starting voltage, load and excitation. There is much more than this involved in the complete starting operation, and the purpose of the present paper is to describe-from the physical point of.view-what actually takes place in the motor windings under a wider range of starting conditions. The information presented in the form of oscillograms is not only interesting in its bearing on synchronous motor operation, but as experimental data jllustrating principles common to alternating-current circuits in general.

Two machines have been used in the experiments described: a 200-kv-a. 2400-volt three-phase 600-rev. per min. standard belted generator and a $150-\mathrm{kv}-\mathrm{a}$. generator of the same characteristics and of the same general design. These two generators have the same number of poles and rotor diameter and, in fact, use the same rotor punchings, so that the design proportions are very closely the same. Both generators are provided with a copper damper winding of the general type shown in Fig. 1. These machines, having been designed as belted generators, have only average performance characteristics as self-starting synchronous motors. The damper winding is of low resistance to serve as a damper during synchronous operation, and as a starting winding for usual synchronous-motor applications where the initial starting torque is not large. 
The complete starting opcration may be conveniently divided into three parts, as follows:

1. Motor starting from rest at reduced voltage and no excitation.

2. Motor running on partial voltage without excitation in synchronism; excitation then applied.

3. Motor running on partial voltage, excited, and in synchronism; voltage then increased to normal line voltage.

There are two additional variations of the third part of the starting operation which can most conveniently be classed as additional parts, as follows:

4. Motor running on partial voltage, without excitation, with external load, field not excited and motor not in synchronism; field then excited and synchronism attained and full voltage applied.

5. Motor running on partial voltage, with external load, excited, but not in synchronism; line voltage then applied and synchronism attained.

The subject will be treated under headings corresponding with these five parts of the starting operation.

I-Motor Starting from Rest at Reduced Voltage; no - External load

(a) Field Circuit Open. This condition is shown by Fig. 2. The motor is started by the application of approximately $\frac{1}{3}$ normal voltage with the field open-circuited and with no external load. A shunt transformer, connected across the field terminals, affords a record of the voltage by the oscillograph. It will be noticed that the maximum current of 106 amperes resulting from the application of voltage is maintained at an approximately constant value until the motor is well up to synchronous speed. The voltage induced in the field winding, as is well known, is a maximum at start and has a frequency equal to that of the supply circuit, the frequency gradually decreasing until it becomes zero when the motor is in synchronism. The voltage is proportional to the rotor frequency, or slip.

(b) Field Circuit Closed. The conditions shown by Fig. 2 are duplicated in the oscillogram Fig. 3, except that the field is closed through its rheostat, the combined resistance of the rheostat and field winding being approximately $8.5 \mathrm{ohms}$. The armature current is slightly increased, having a value of 120 amperes instead of 106 amperes. A current of 10 amperes (maximum 
PLATE $X X X$

A. I. E. E.

VOL. $X \times X I 1$, NO. 6
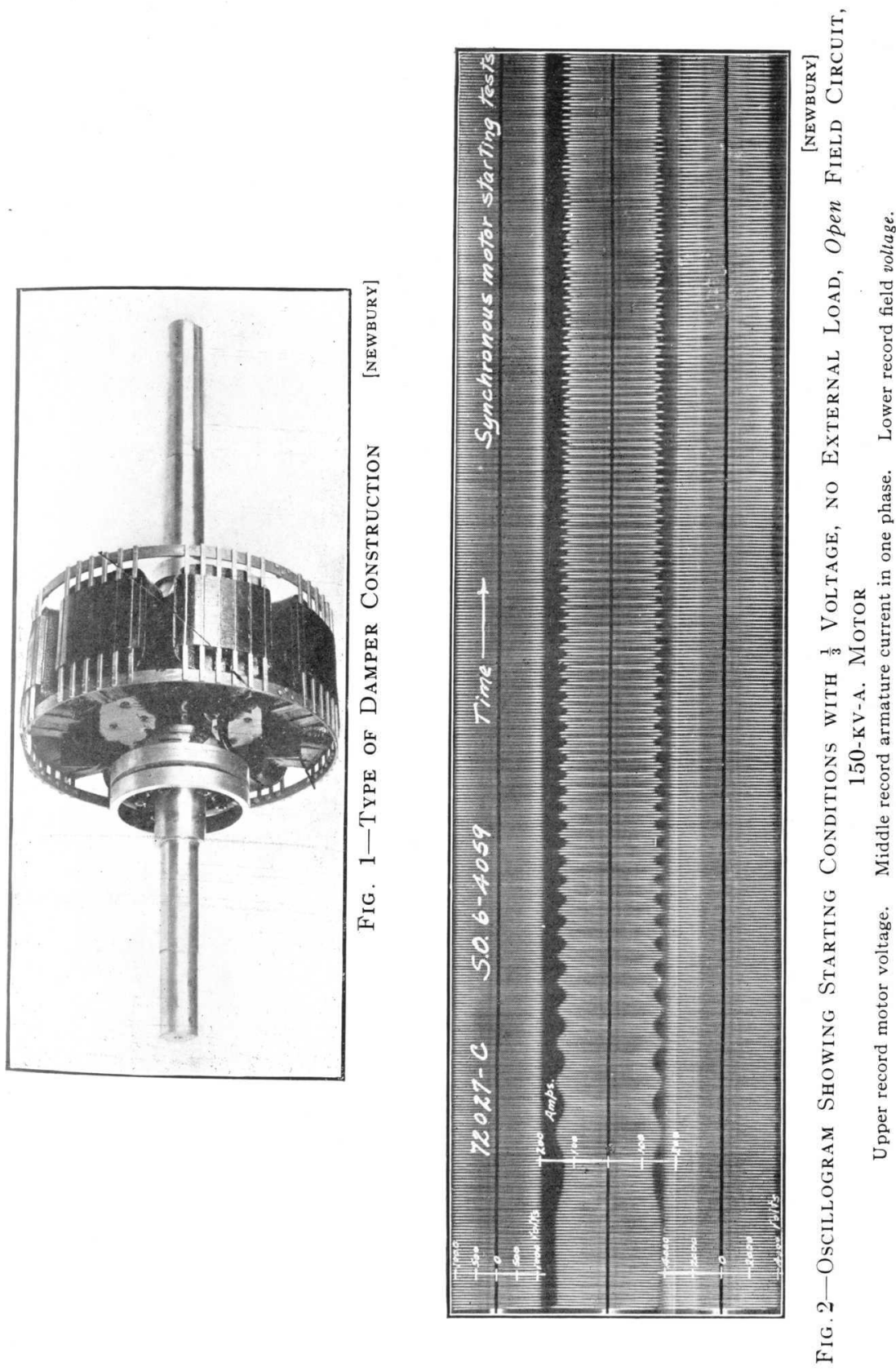

PLATE $X X X \mid$

A, I, E, E.

VOL. $X X X I I$, NO. 6
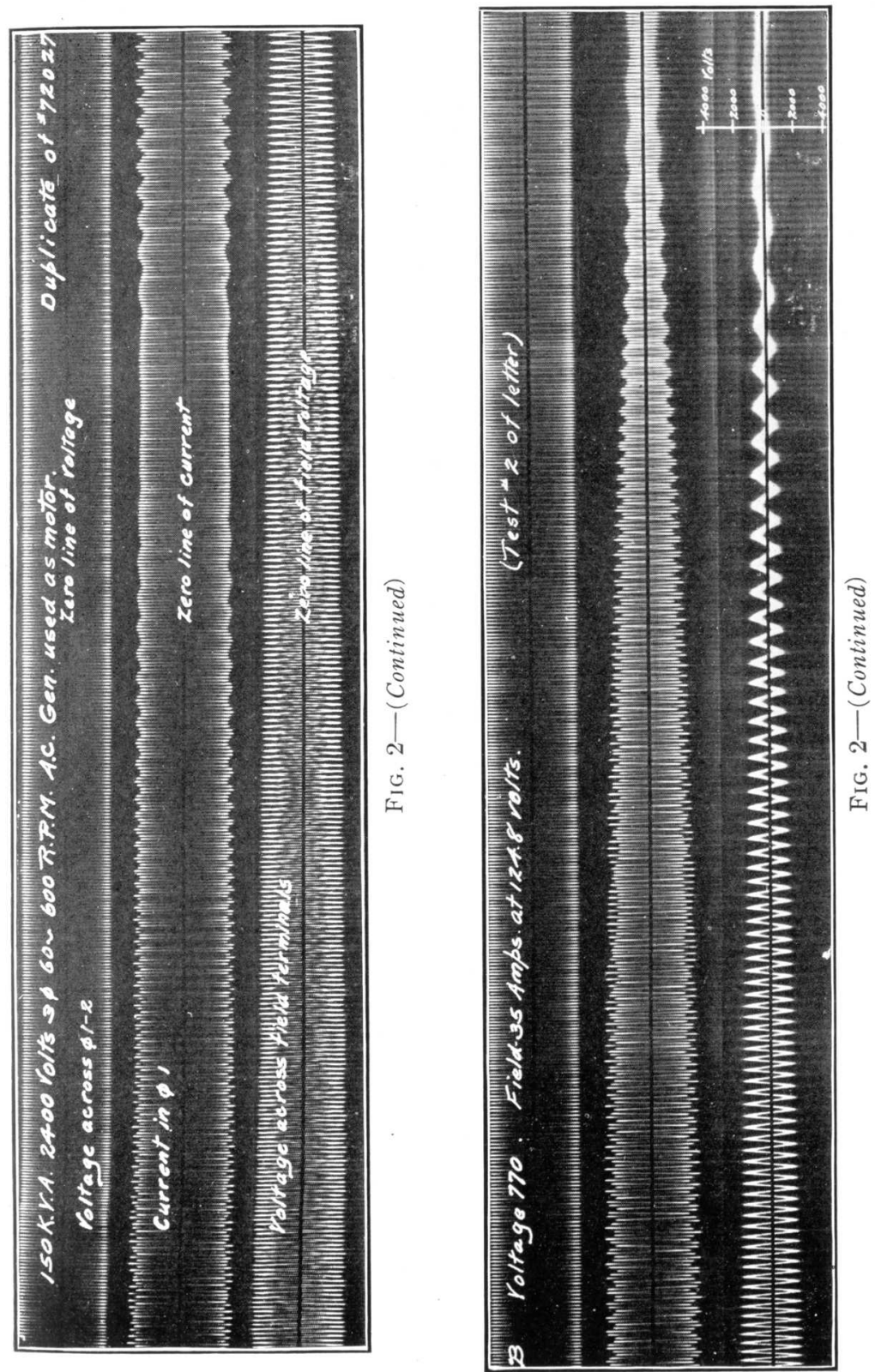

PLATE $X X X I I I$

A. I. E. E.

VOL. $X X X I I$, NO, 6

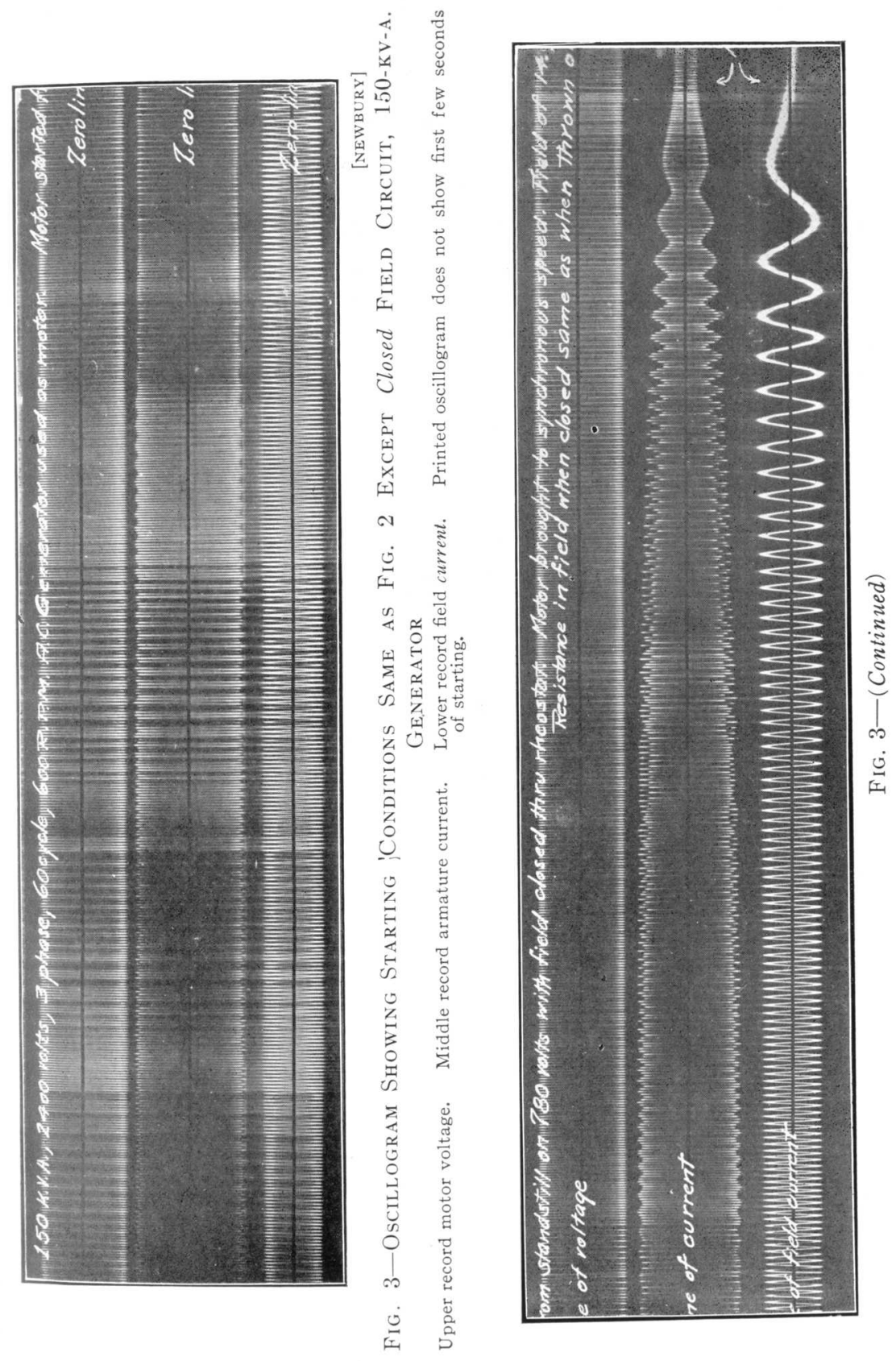



PLATE XXXIV

A. I. E. E.

VOL. $X X X I I$, NO. 6
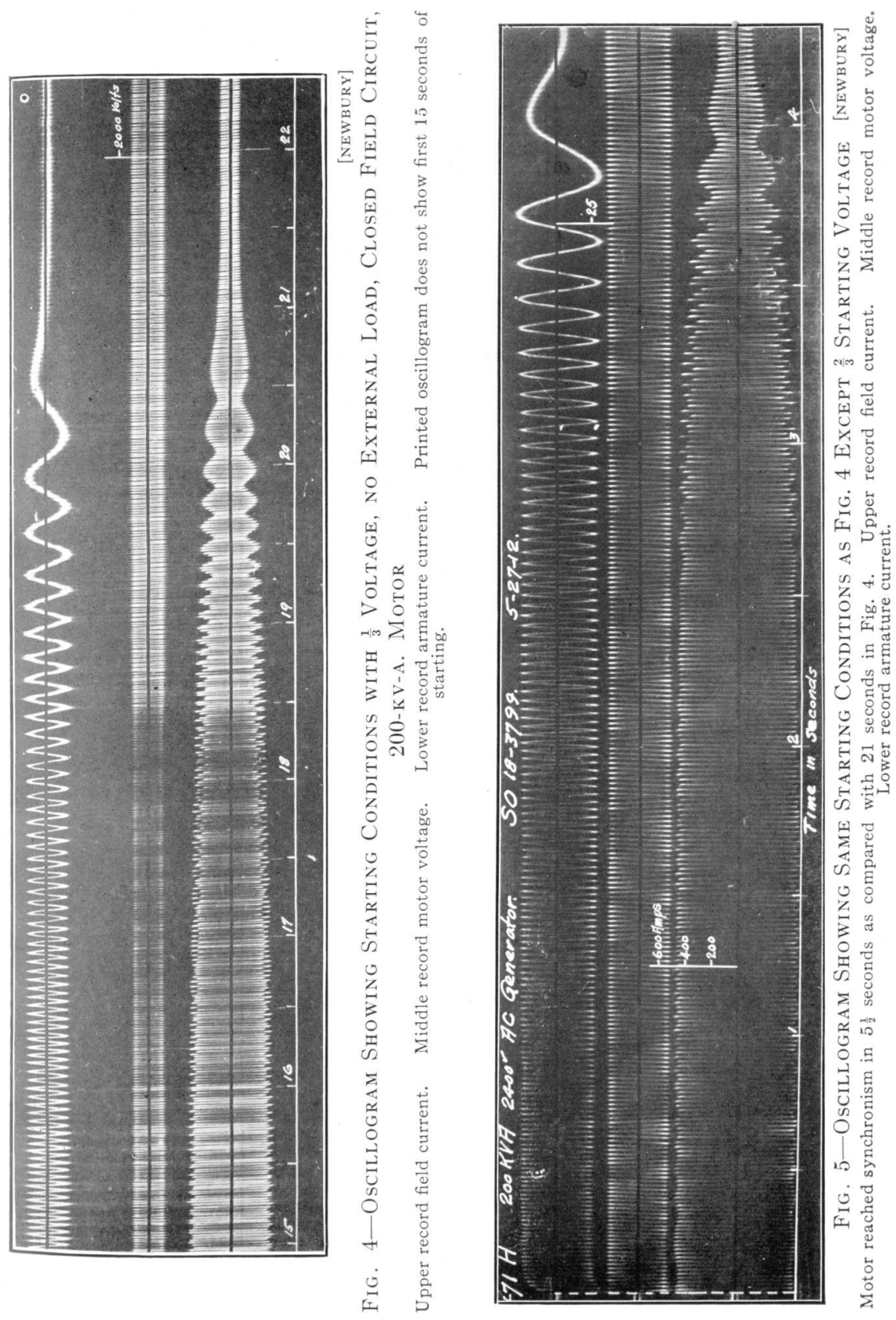

value) is induced in the field winding and is maintained at this value until the motor is within a few per cent of synchronous speed. This field current is alternating, and, like the field voltage in Fig. 2, has a frequency equal to the slip. There is a pulsation in the armature current corresponding to the frequency of the current in the field circuit, these pulsations becoming very pronounced near synchronism. Although the value of the voltage induced in the field circuit is proportional to the slip, as shown in Fig. 2, the current is practically constant due to the

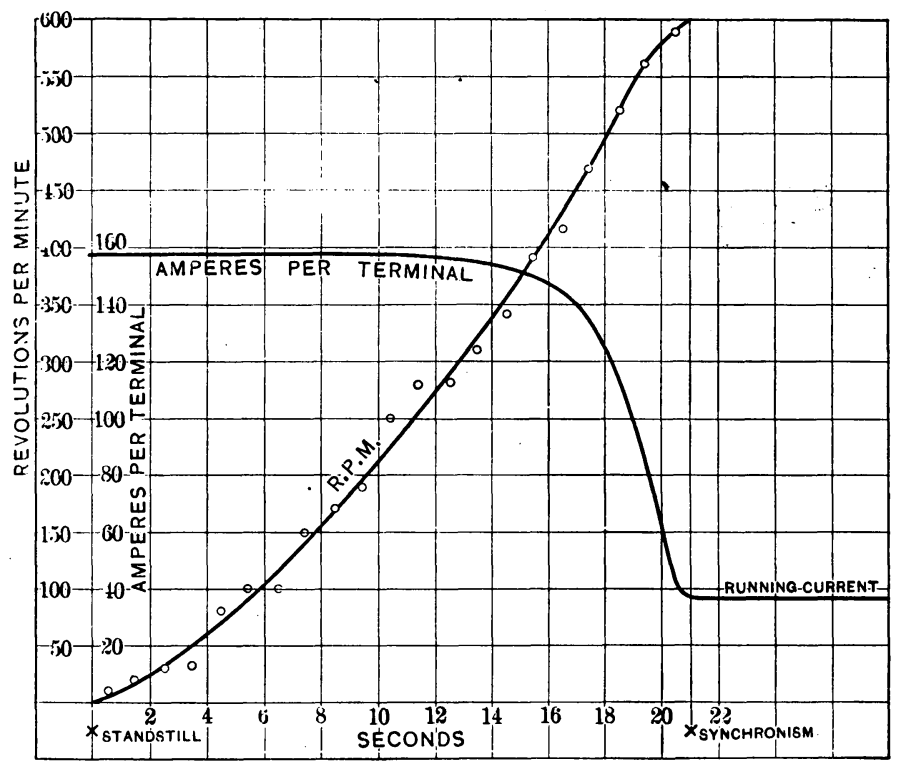

Fig. 6-Speed and Current During Starting under Conditions OF FIG. 4

reactance of the field winding and the voltage decreasing at the same rate. The constant resistance of the field circuit has a negligible effect until the reactance has become practically zero near synchronism. This illustrates very clearly the reason why resistance connected in the closed field circuit has practically no effect on the armature current and torque until the resistance has been made at least equal to the reactance at normal frequency. Figs. 2 and 3 show results from the 150-kv-a. motor. Similar results from the $200-\mathrm{kv}$-a. motor with closed field circuit are shown in Fig. 4, with $\frac{1}{3}$ normal voltage, and Fig. 5 , for $\frac{2}{3}$ normal 
voltage. The fact that the frequency of the current induced in the field winding is equal to the slip makes it possible to plot a curve showing the relation between speed and time. Such a curve plotted from the oscillogram in Fig. 4 is shown in Fig. 6 for $\frac{1}{3}$ voltage, and from the oscillogram in Fig. 5 is shown in Fig. 7 for $\frac{2}{3}$ voltage. To these curves have been added the current curves which illustrate the point already made, that the maximum current is maintained at a constant value until synchronism is nearly reached.

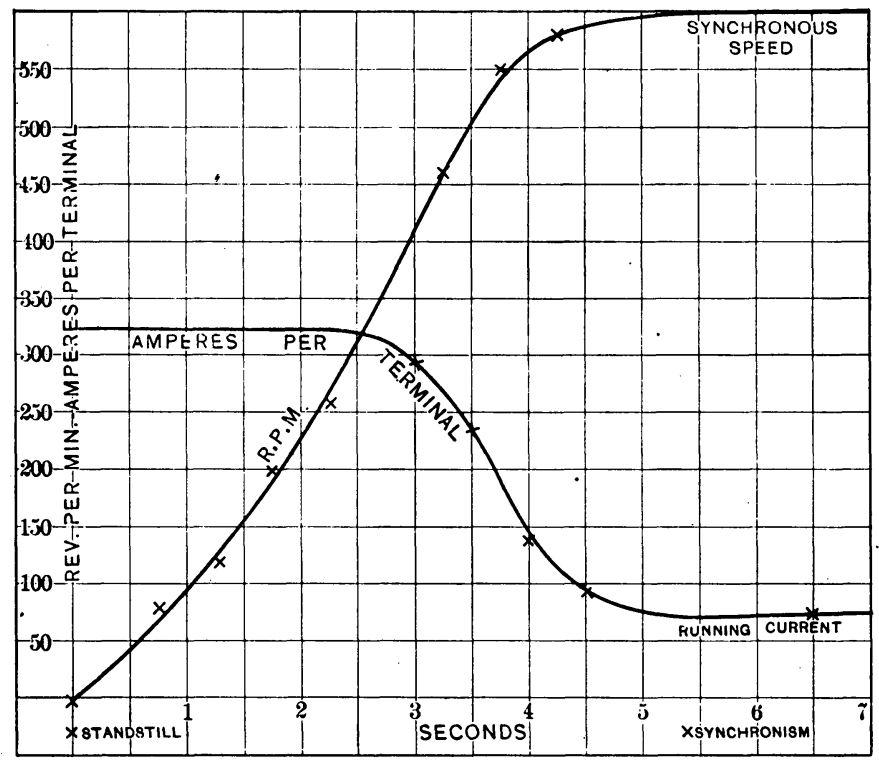

Fig. 7-Speed and Current During Starting under Conditions OF Fig. 5

The effect of the closed or open field circuit on the torque 7 veloped is shown in Figs. 8 and 9 for the $150-\mathrm{kv}-\mathrm{a}$. motor. Fig. 8 shows the current and kilowatts existing when varying voltage is applied to the armature, the rotor being locked. Under these conditions, the observed kilowatt minus the armature loss represents the loss in the rotor, and this in turn is proportional to the torque developed at the instant of starting. With the field circuit closed, the loss due to the single-phase current in the field winding is not effective in producing torque, so that the two curves are not exactly comparable. The loss in the field winding, 
however, is negligible, so that this fact does not appreciably affect the statement made. It will be noted that the rotor loss is slightly greater with the field short-circuited than with the field opencircuited, showing that the short-circuited field, at least, has not been a serious detriment to the development of torque.

In Fig. 9, the starting torque is shown directly as measured by brake-beam and scales for a 150-kv-a. motor of the same design, except with a different armature winding for 440 volts.

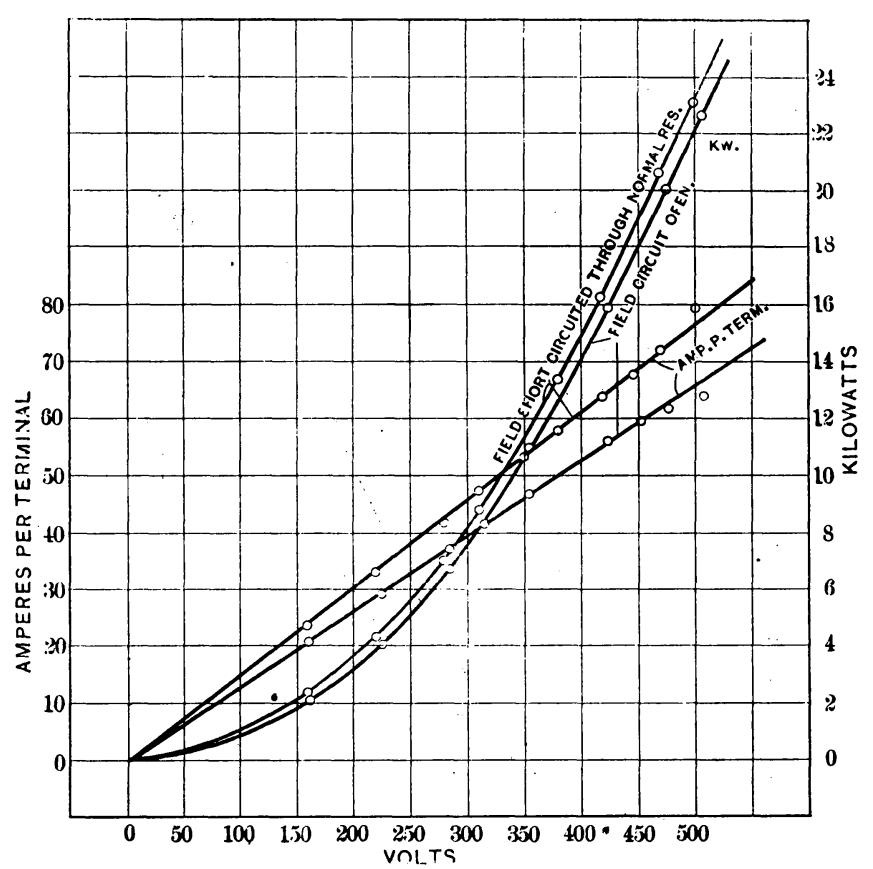

Fig. 8-Comparative Starting Torque with Closed and Open

Field CirCUIT-150-KV-A. MOTOR-COPPER DAMPER WINDING

The armature turns, however, in the two motors are proportional to the voltages. Torque curves are shown with the field circuit closed and with the same damper winding as used in the motor used in the oscillograph tests, and with a damper winding composed of brass bars instead of copper bars. With the latter damper winding, the curves show a material increase in torque with the field open as compared with the field closed.

Figs. 8 and 9 illustrate a condition generally true: that with an effective low-resistance damper winding the torque and armature 
current are very little affected by the closed field circuit, but that with a high-resistance damper winding, or with a rotor construction that permits only an ineffective damper winding to be used, the closed field circuit has a marked effect in reducing the initial starting torque. The field winding may be considered as an additional winding in parallel with the squirrel cage winding. Whether it has an appreciable effect in decreasing the torque for

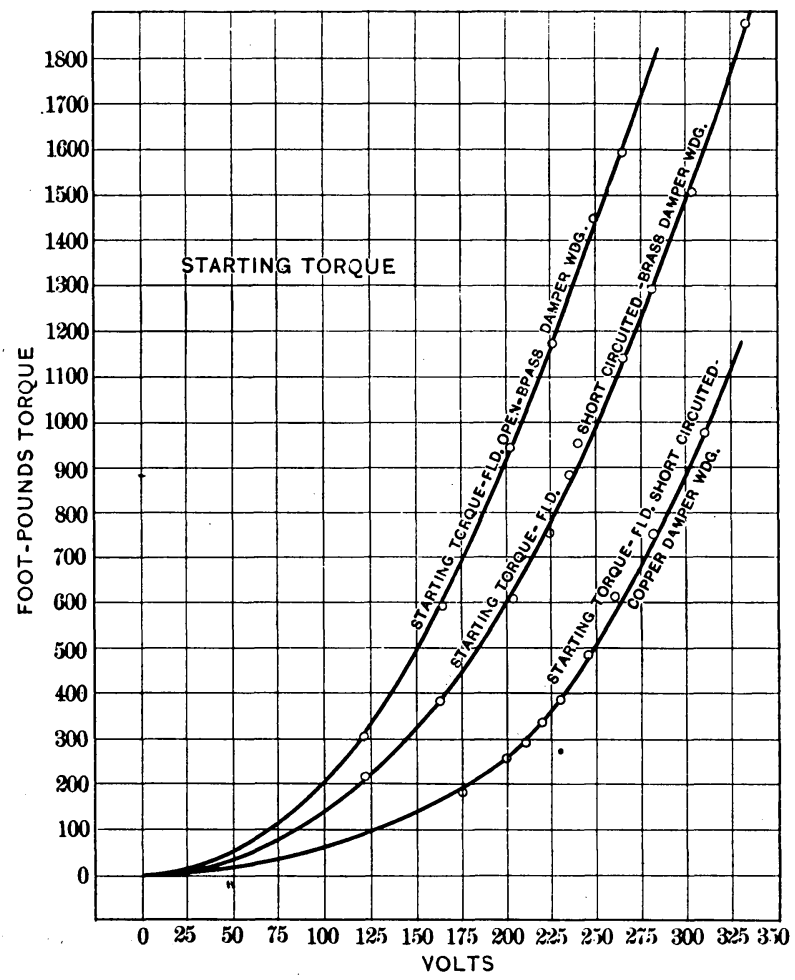

Fig. 9-Comparative Starting Torque with Closed and Open Field Circuit, High and Low Resistance Damper Windings

a given voltage depends simply on its resistance compared with that of the squirrel cage winding and the relative currents in the two windings. It is of interest to note that with a combination of field and damper windings such that the closed field winding has an appreciable effect on the torque developed, there is a considerable tendency for the motor to lock at half speed, the effect being the same as a phase-wound induction motor with one phase open-circuited. 
PLATE XXXV

A. I. E. E.

VOL. $X X X I I$, NO. 6
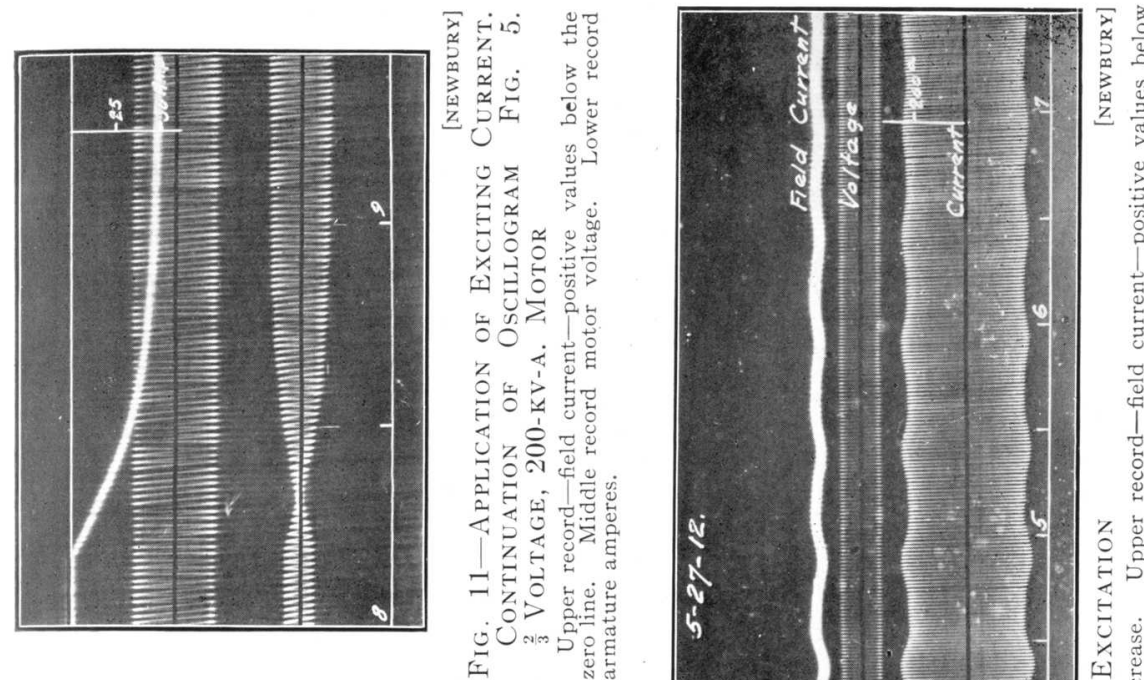

$\stackrel{\square}{\varpi}$

$$
\text { a }
$$

di

는

के

t

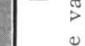

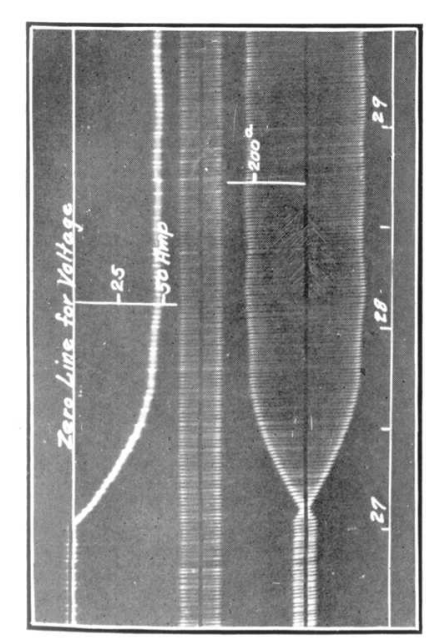

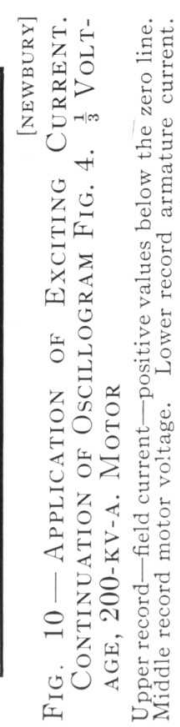

v

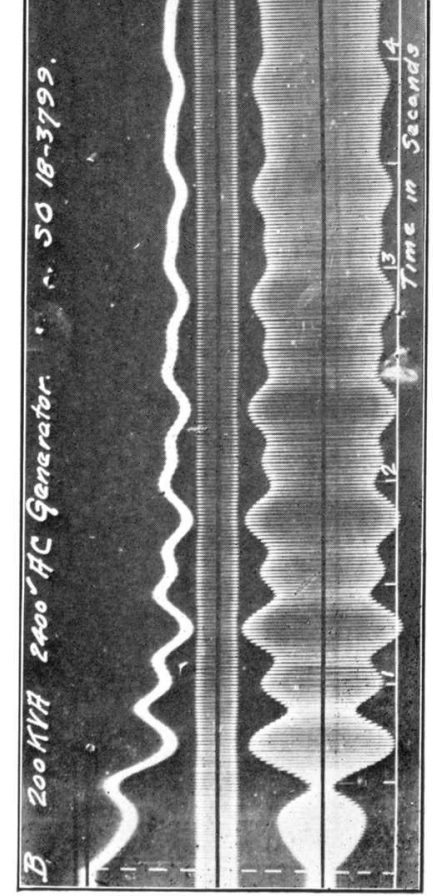

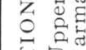

E.

t5.

(

วั ษ

द

0

년

( )

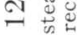

0 ن v

t5

过

드응

bo

莺

范

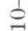

$\stackrel{0.0}{2}$

政

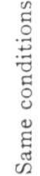



PLATE XXXVI

A. I. E. E.

VOL. $X X X I I$, NO. 6
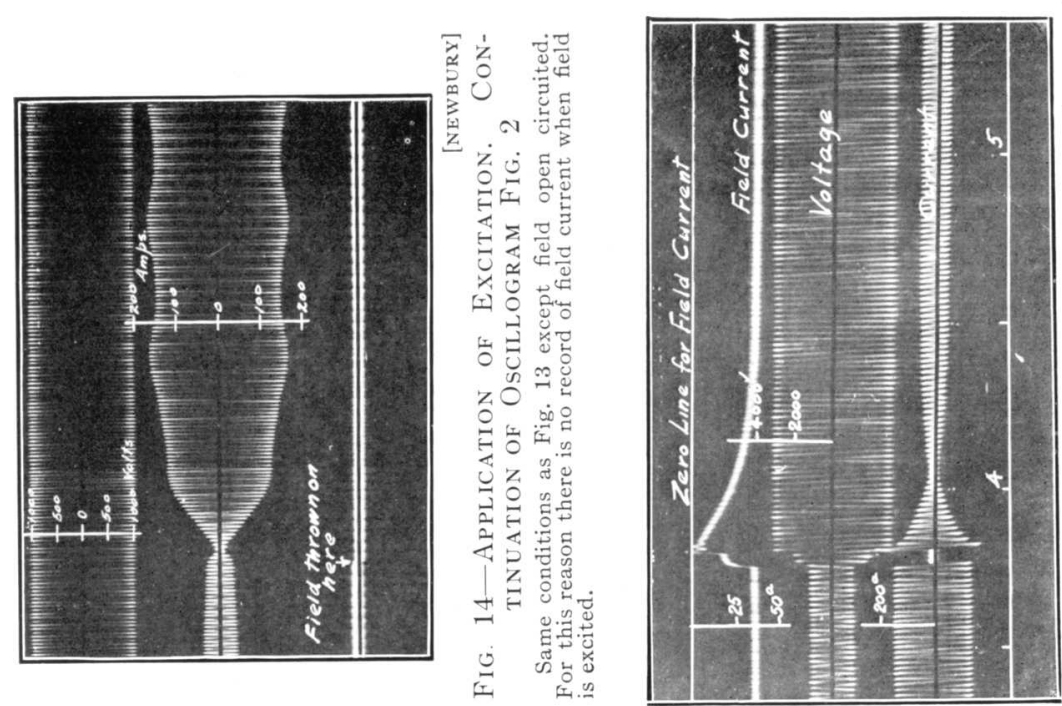

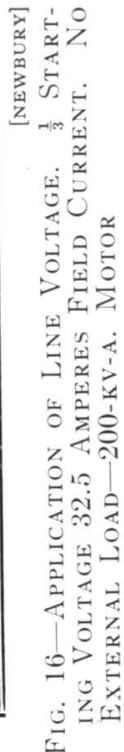
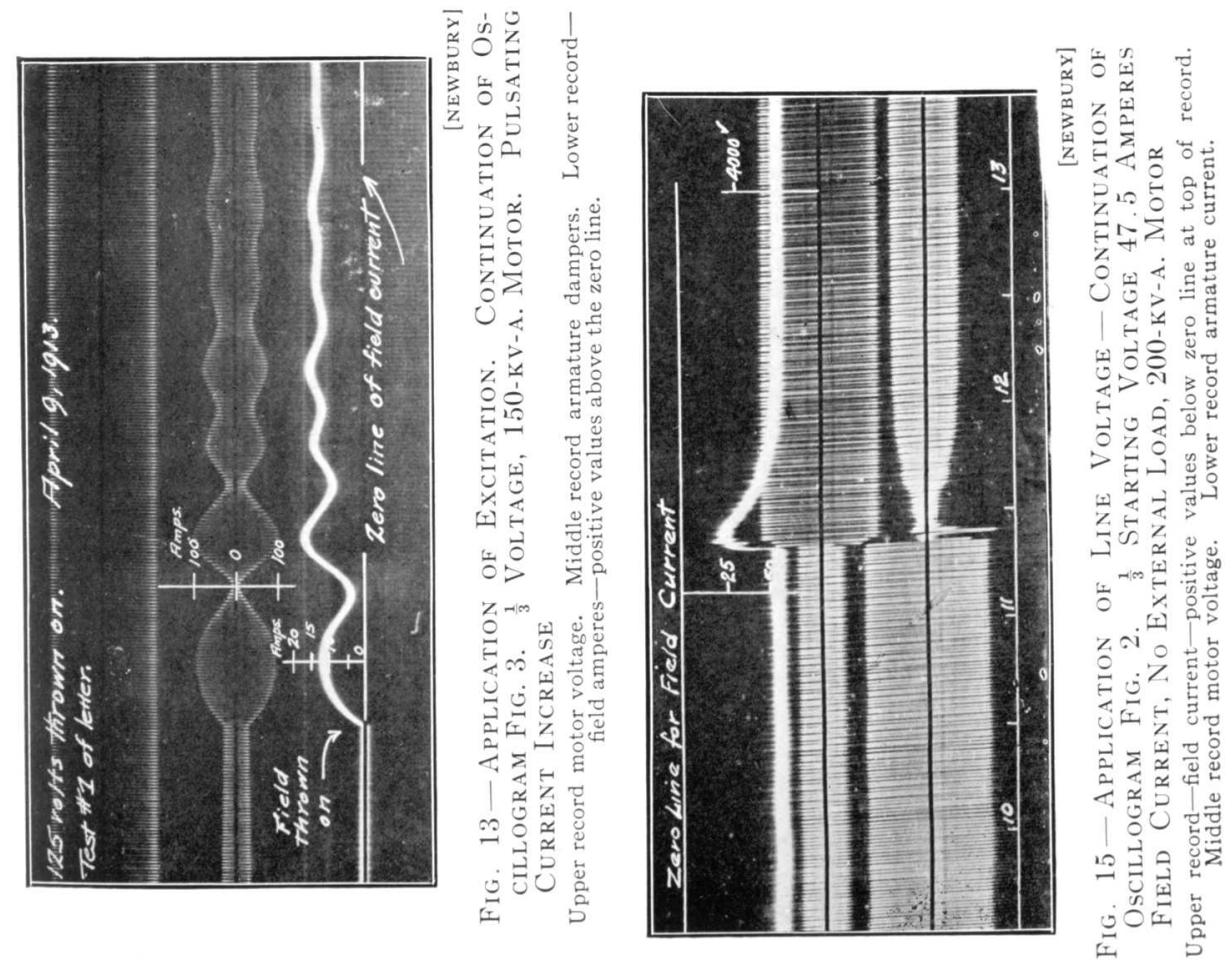

PLATE XXXVII

A. I. E. E

VOL. $\times X X X I I$, NO. 6
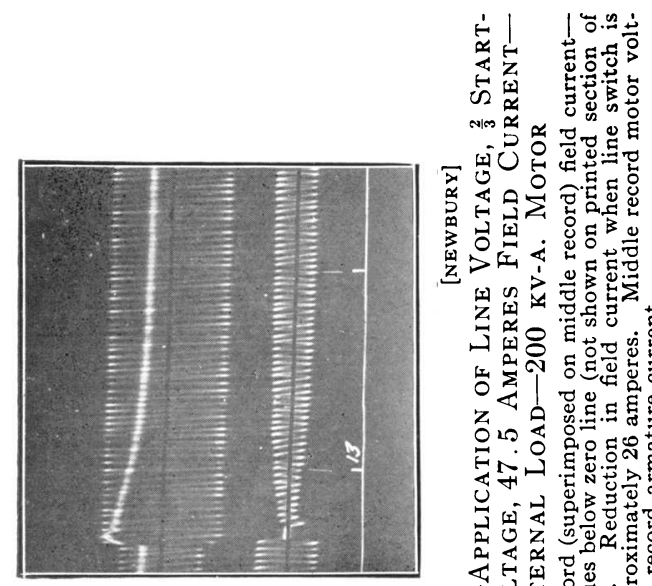
$\rightarrow$ 둬월

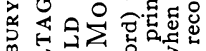
思

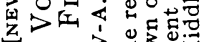

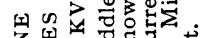
Z

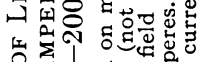
र ㄴ.

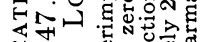
บㅂ 일

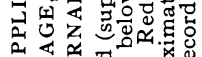

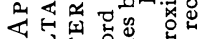

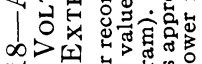

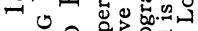

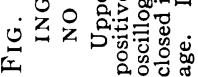

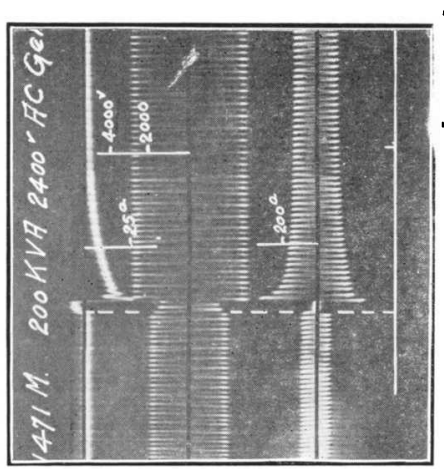

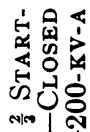
त्र 5

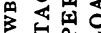
罗它最 $>$ ४ 四年 星国 近质 당 (되 긍웅을 촌 युำ

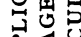

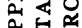
द 40 워웜웡 ن苔里䛼
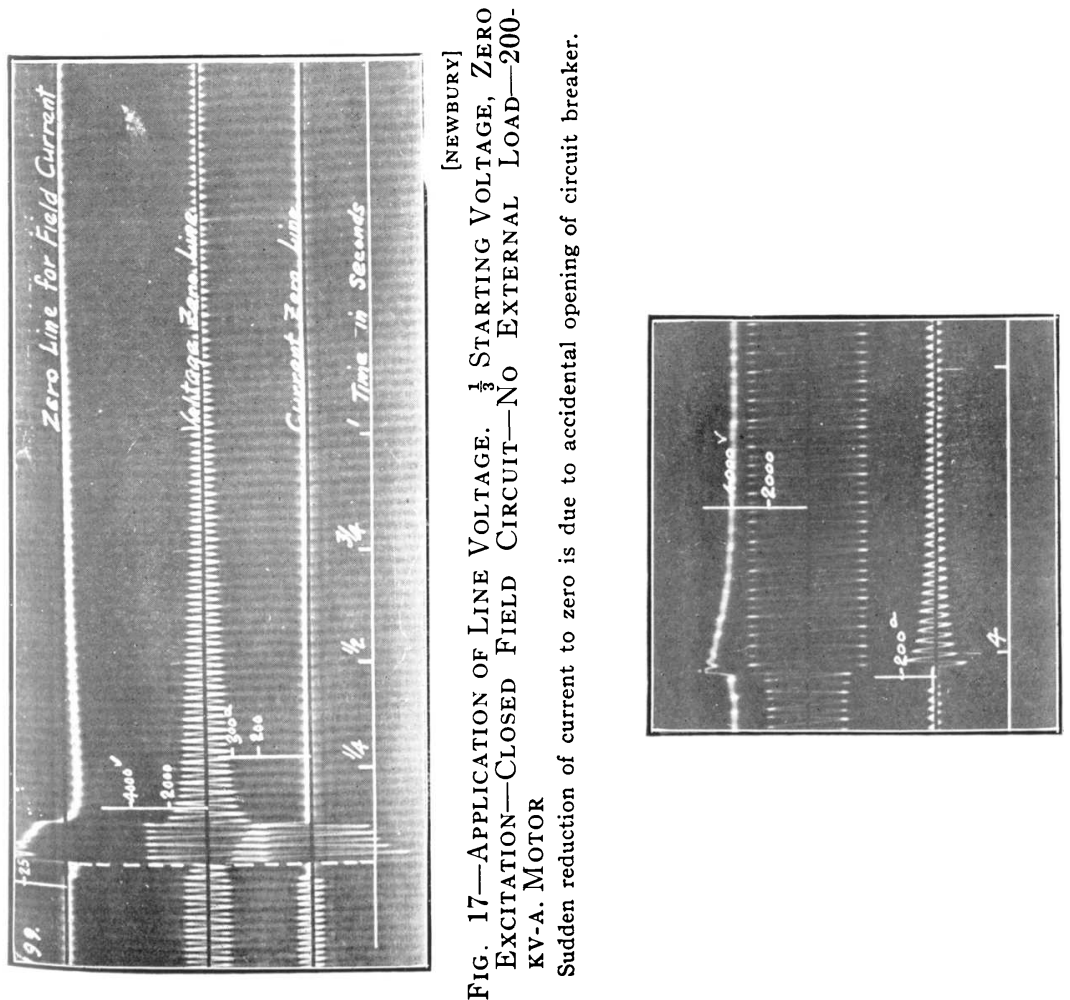
不咨

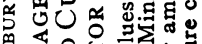

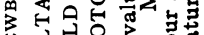
田司国 品

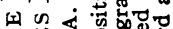

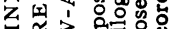
今 되 1司导

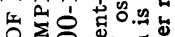

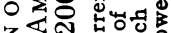
乙र 象 9 .

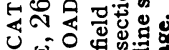
늠임

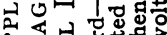

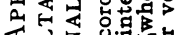

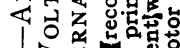

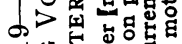
- U凶x

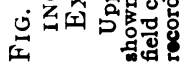



PLATE XXXVIII

A. I. E. E.

VOL. $X \times X I I$, NO. 6

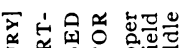

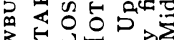

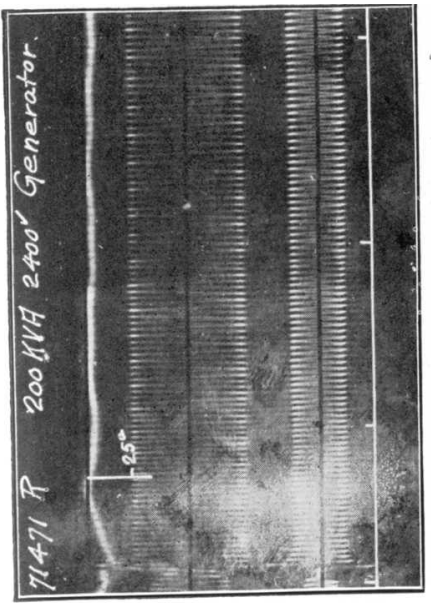

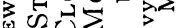
Nen

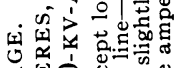

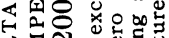

इ

$>$ ४

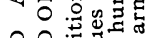

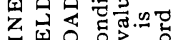

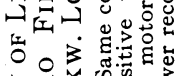

$\mathrm{z}$ 蛇

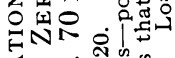

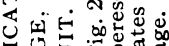

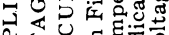

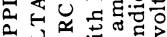

येठ

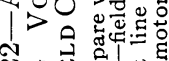

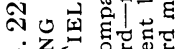

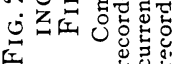

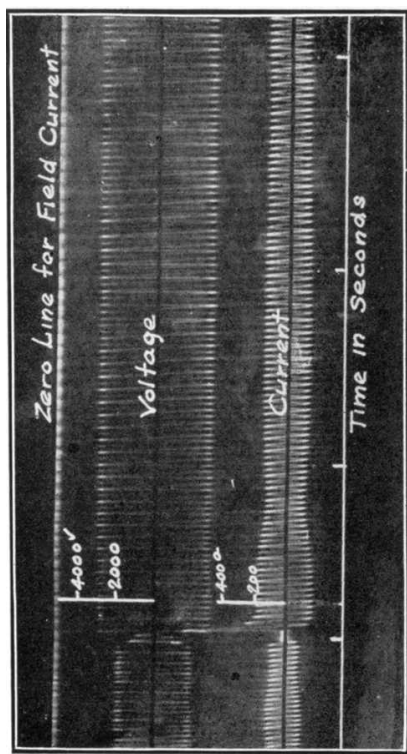

₹ 송여

在 思学

욍 응

○ั

宓 总

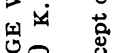

웅

임

四岕 营

侌。

占 密

$z$ z

엻 ส

范出

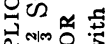

究.

㱐

仓ิن نे

至

¿

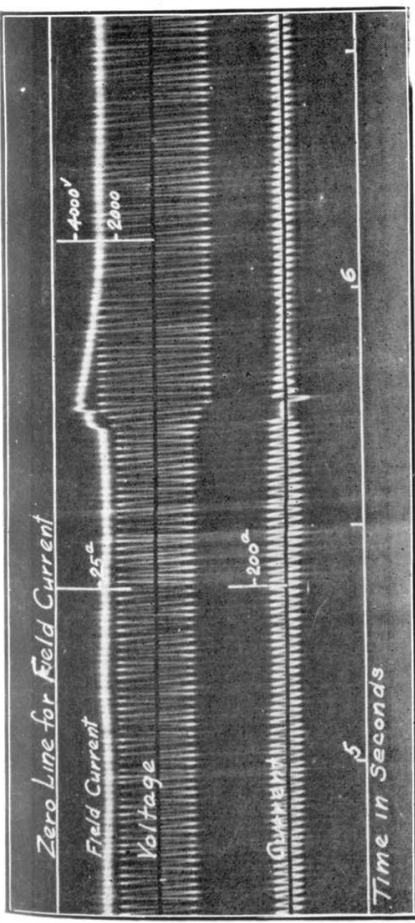

6

国 红

z约

०ิ

जे

응응

중 뭉

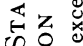

Nim 0

더욤

48

잉

(I)

岁安的

되

농 중

$\mathrm{z}$

ค

记望

可

a.

$\frac{4}{x}$

골

s.

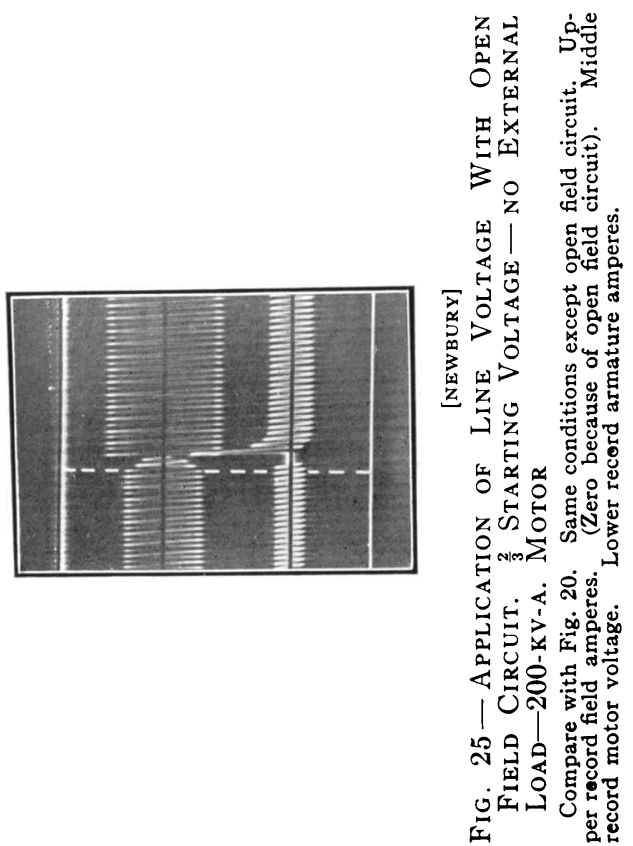



It will be noted in Fig. 2 that the induced voltage has a value of approximately 4000 volts maximum, or 2800 volts, effective value. With a higher exciting voltage, requiring more turns in the field winding, or with a higher resistance damper winding, this voltage would have been considerably higher. For selfstarting synchronous motors started with the field circuit open, the present standard insulation test of 5000 volts may be exceeded in many cases by the actual voltage obtained in operation, and in few cases does it give the same factor of safety that is given by the standard tests for the armature winding.

These facts show the desirabjlity of starting synchronous motors with the field circuit closed (and so eliminating the high voltage from the field winding and switchboard), except in special cases where unusually high initial starting torque is required. For such applications a high resistance damper winding is necessary, the benefits of which in producing torque would be largely nullified by the closed field circuit. In such special applications, however, care must be taken to insure that the insulation of the entire field circuit will withstand the resulting voltage.

\section{II-Motor Running on Partial Voltage with Closed or \\ Open Field Circuit with no External Load and in Synchronism; Field then Excited}

With the motor running with zero field current in synchronism, the effect of the application of exciting current is shown in Figs. 10, 11, 12 and 13. Fig. 10 and Fig. 11 show results with the 200-kv-a. motor and are continuations of the same oscillograms shown in Figs. 4 and 5. These oscillograms show a gradual increase in field current and a preliminary decrease followed by a steady increase in the armature current. Fig. 12 duplicates exactly the conditions of Fig. 10 but the results are markedly different. The armature current immediately starts to increase instead of first decreasing as in Fig. 10, and reaches its final value only after successive pulsations lasting 8 or 9 seconds. The field current, instead of steadily increasing to its final value as in Fig. 10, pulsates synchronously with the armature current. When steady conditions are attained, however, the values in Figs. 10 and 12 are substantially the same. Fig. 13 shows a similar result with the $150-\mathrm{kv}-\mathrm{a}$. motor.

An examination of a large number of oscillograms taken shows no fixed relation between the occurrence of the steady increase in field current and armature current as in Fig. 10 or the pulsating 
increase as in Figs. 12 and 13, and other conditions of operation. The most reasonable assumption is that the steady increase occurs when the field current and armature current at the instant of closing the field switch agree in polarity, and that the pulsating condition occurs when they do not so agree. The immediate increase in armature current in Fig. 12 when exciting current is applied is, under this assumption, required to maintain the necessary net excitation required for the applied voltage and flux. The succeeding decrease in armature current is caused by the rotor " slipping a pole" to bring the armature and field excitations in phase. The relative change in armature and field polarity requires a decrease in field excitation to maintain constant, flux, as shown by the oscillogram. If, when the rotor "slipped a pole," it remained in synchronism with the armature, the armature and field currents would gradually increase to their final steady value, as in Fig. 10. The succession of pulsations shows that the rotor oscillates back and forth, succeeding oscillations decreasing in amplitude until the rotor settles into its final relative position.

In all of the oscillograms so far shown, the excitation has been much more than that required to maintain minimum armature current with 100 per cent power factor, so that the final steady value of armature current has been greater than that required with zero rotor excitation.

\section{III-Motor Running on Partial Voltage, Excited and in Synchronism, With and Without External Load; Line Voltage then InCREASEd to Normal}

This condition is shown by Figs. 15, 16 and 17, representing an initial voltage $\frac{1}{3}$ of normal and no external load on the motor; Figs. 18,19 and 20 representing an initial voltage of $\frac{7}{3}$ normal and no external load on the motor; and Figs. 21 and 22 representing an initial voltage $\frac{2}{3}$ of normal and with approximately $\frac{1}{3}$ full load on the motor.

The change from the initial starting voltage to normal voltage is made by a double-throw switch. The armature circuit is momentarily opened in throwing from the low voltage to the high voltage and current drops to zero during this interval. The voltage, instead of also dropping to zero, as might be expected, increases or decreases, depending on the value of the field current. During this same interval the field current shows a marked decrease in some cases and an increase in other cases due to change in armature current. 
The oscillograms taken do not show zero voltage during the interval the line switch is open because the counter e.m.f. of the motor is recorded. Since, during this interval, the motor is not connected to the supply circuit, the counter e.m.f. will follow the field excitation alone rather than the combined magnetizing effect of the field and armature currents; thus in the oscillograms representing excess field excitation the counter e.m.f. of the motor will increase (see Fig. 15, 18 and 21), and in oscillograms representing the under-excited condition the counter e.m.f. of the motor will decrease (see Figs. 17, 20 and 22).

When the switch is closed, applying the higher voltage to the motor, there is a momentary rush of current which may either decrease to a minimum value and then gradually increase to the steady value, or may gradually decrease to the steady value. At the instant of application of the higher voltage, the field current decreases and then steadily increases to its original directcurrent value.

The reason for these relative changes in voltage and current will be clear when it is remembered that the field winding constitutes a closed circuit in inductive relation with the armature circuit and currents will flow in this circuit in a direction to oppose any change in the flux through the circuit. Thus when the armature voltage is changed, requiring a proportional change in flux, the induced current in the field circuit will decrease the existing current if the flux is increased, and will increase the existing current if the flux is decreased. This is true whether the existing field current is more or less than required for unity power factor. The relative changes in field and armature current when the switch is opened may be -similarly explained. If the motor is over-excited, as in Figs. 15 and 18, the existing armature current has a large demagnetizing component. When this is removed by opening the switch, the flux tends to increase so that the current in the field winding decreases. On the other hand, if the motor is under-excited, the out-of-phase component of the armature current is magnetizing and when this is interrupted the flux is decreased and the field current is increased.

In the operation of synchronous motors, it has been noticed that the current rush in changing from the starting voltage to the running voltage, the motor being in synchronism on the low voltage, is much larger with small field excitation than with large field excitation. In some cases the current taken by the motor with small field excitation has been sufficient to open the circuit 
breakers or damage the starting equipment. Various theories have been advanced for this observed fact, most of them involving the different phase relations existing with different excitations. The series of tests under discussion, however, show that this factor has little, if any, effect on the current taken by the motor under the operating conditions imposed, and that the real explanation is very simple. It will be noticed in Figs. 15, 18 and 21 , showing the action with maximum field excitation, that the counter e.m.f. of the motor during the interval that the switch is open increases to meet the higher voltage applied when the switch is closed. In Figs. 17, 20 and 22, illustrating the action with zero excitation, the opposite effect on the counter e.m.f. is observed, the counter e.m.f. falling as soon as the switch is opened. Due to this behavior of the counter e.m.f., there exists only a small difference between the counter e.m.f. of the motor and the high line voltage at the instant the switch is closed when the motor is over-excited, and there exists a large difference when the motor is over-excited. To check this point quantitatively, the maximum voltage difference at the instant of closing the switch and the maximum current rush were measured on about 20 oscillograms and the results plotted in Fig. 23. This curve shows an approximate proportional relation between the increase in current and increase in voltage, irrespective of the difference between applied starting voltage and applied normal line voltage, and irrespective of the load on the motor, up to the value of load used in the tests.

Whenever the phase relation between current and voltage is changed, as, for example, when the voltage is changed with constant excitation, there is a corresponding change in space relation between the rotor and the magnetic field established by the stator which requires a change in torque and current to accomplish it. The fact that the load upon the motor does not affect the current rush shows that this factor does not have a controlling effect on the current taken by the motor. Again, the rotor will slow down during the interval the armature circuit is open, which may increase or diminish the required change in rotor position. This also has had very little, if any, effect on the current in the tests made but the interval between opening and closing the switch is very short, less than two cycles, and with a longer interval this factor might easily become the controlling one. Later on, oscillograms will be shown (Figs. 27 to 30 ) illustrating the action with larger loads, and the effect of phase position will be found to be of controlling importance. 
The relation between the maximum armature current at the instant of change in voltage and the field excitation is shown in Fig. 24 for two starting voltages and with no external load on the motor. These curves have been drawn in such form that they represent the familiar $V$ curves of synchronous motors with the addition of the maximum instantaneous current curves. This maximum current curve shows graphically the large increase in maximum current with small field excitation. From these curves the armature currents for the various stages of the starting operation can be obtained for any value of field excitation;

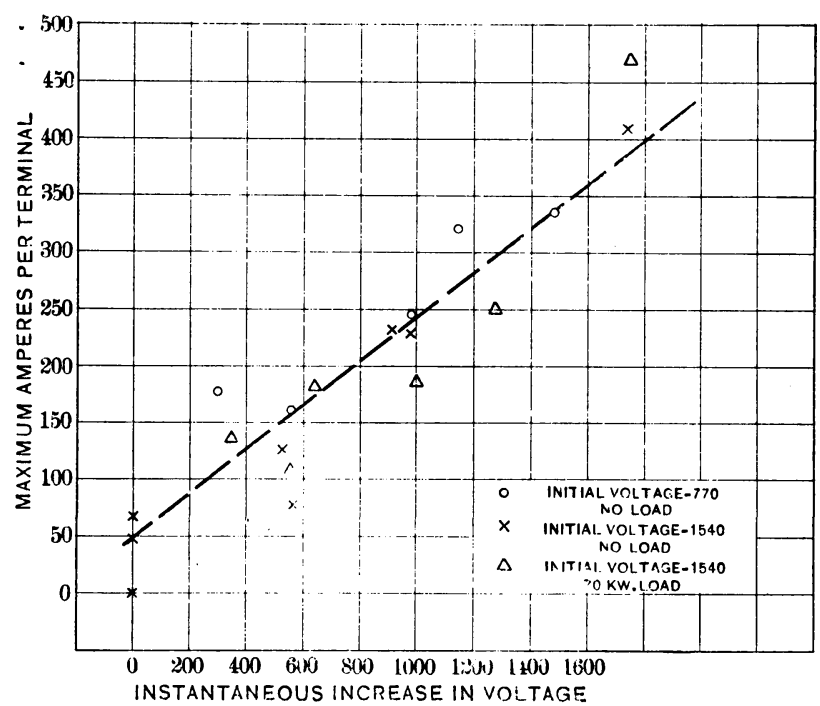

Fig. 23-Relation Between Instantaneous Change in Voltage and Current for Three Starting Conditions. 200-kv-a. Motor

for example, with 40 amperes field excitation the motor will take a steady current of 125 amperes (curve $A$ ) on $\frac{1}{3}$ starting voltage. In throwing over to normal voltage, the maximum current will be 162 amperes (curve $B$ ) and will settle to a steady value of 57 amperes (curve $C$ ). Similarly, when starting on $\frac{2}{3}$ voltage instead of $\frac{1}{3}$, and with the same excitation, the motor will take a steady current of 95 amperes (curve $D$ ) which will decrease to the value of 46 amperes (curve $E$ ) when thrown on full voltage and will then increase slightly to 57 amperes (curve $C$ ) as the steady running value. The initial starting currents (not shown in Fig. 24) are 159 amperes at $\frac{1}{3}$ voltage and 328 amperes 
at $\frac{2}{3}$ voltage. Fig. 24 illustrates the major importance of field excitation in reducing the maximum instantaneous armature current when the voltage is changed from the low to a high value. As a matter of fact, the field excitation may have a greater effect on the maximum armature current than the difference between starting and running voltages. It is usually considered of ad-

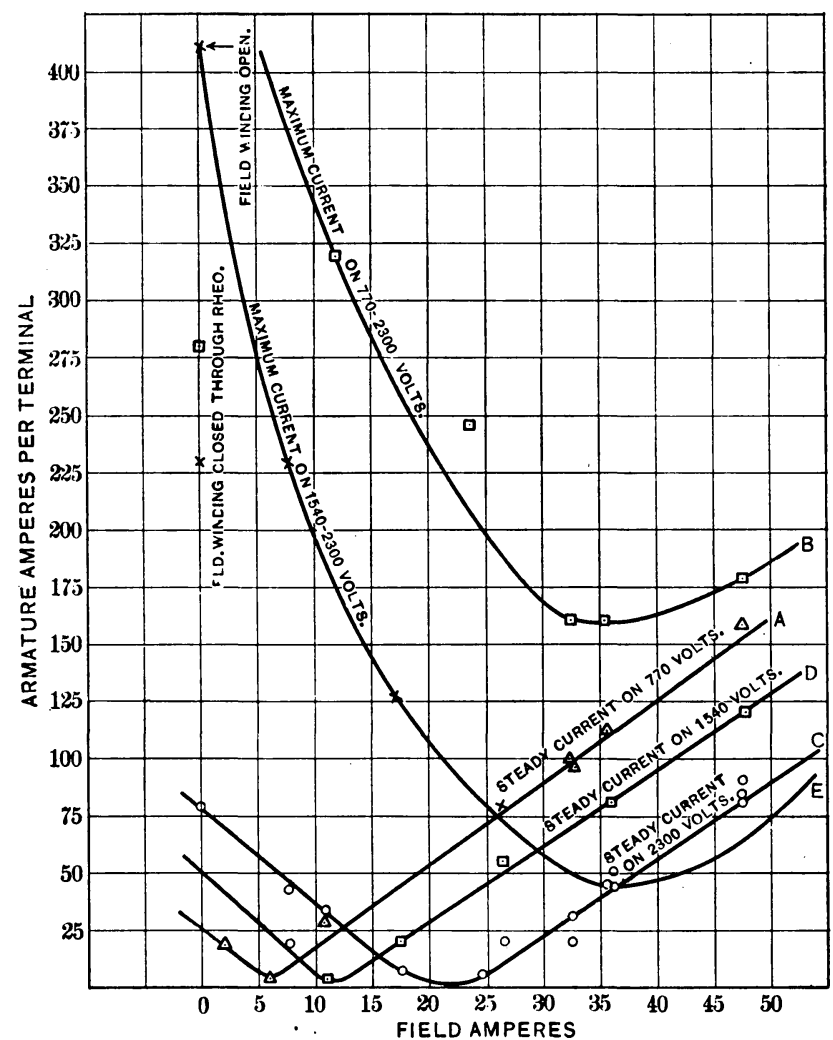

Fig. 24-Relation Between Armature Currents and Field CurRENTS- No External LOAD-200-KV-A. Motor

vantage, in reducing the maximum current, to use two starting voltages instead of one; that is, starting on $\frac{1}{3}$ voltage, changing to $\frac{2}{3}$ voltage and then applying full voltage instead of applying full voltage immediately after starting on $\frac{1}{3}$ voltage. Fig. 24 shows, however, that with two starting voltages and low excitation the current rush may be greater than with one starting 
voltage and high excitation. At 1540 volts and 10 amperes, field excitation, the steady current is 6 amperes which increases to 200 amperes when 2300 volts are applied. On the other hand, at 770 volts and 35 amperes field excitation, the steady current is 106 amperes which increases to 160 amperes when 2300 volts are applied.

For the complete starting operation the minimum starting current is obtained by starting on $\frac{1}{3}$ voltage and throwing over to full voltage after synchronism has been attained and maximum excitation has been applied. Under these circumstances, the maximum current at standstill is approximately equal to the maximum current at the application of full voltage. If $\frac{2}{3}$ voltage is initially applied, the current at the application of full volt-. age is materially reduced, but this is of no operating importance as the initial current is considerably increased. Also, the use of an intermediate starting voltage such as $\frac{2}{3}$ voltage between $\frac{1}{3}$ and full voltage does not result in any advantage, as in changing from $\frac{1}{3}$ to full voltage the maximum current measured by oscillograph is practically the same as at the application of the initial starting voltage. Measured by ammeter, the current at change in voltage is much less than at start.

In discussing maximum starting currents, a distinction must be made between currents measured by indicating instruments and currents measured by oscillograph. At the start the currents measured by these two methods are practically equal since the starting current is maintained at its maximum value for a number of seconds. At change in voltage, however, the current measured by ammeter very often bears no relation to the actual current measured by oscillogram since the maximum current may exist for only a few alterations.

There is one more point of interest in connection with maximum current at change in voltage which may be mentioned. Fig. 20 shows the condition with zero excitation and closed field circuit. Fig. 25 shows exactly the same conditions except that the field circuit is open. Similarly, Fig. 22 shows the same conditions as Fig. 20 except that the motor is carrying an external load. Fig. 26 shows the same conditions as Fig. 22, except that the field is open circuited instead of short circuited. A comparison of these oscillograms shows a marked increase in current rush with open field circuit. This is satisfactorily explained by the restraining effect of the induced field current, in the case of the closed field circuit, on any change in flux. 
IV-Motor Running on Partial Load with Field Short-Circuited with External Load bUt not in Synchronism; Field then Excited and Synchronism Attained; Full Voltage then Applied

In the cases previously considered, the motor is in synchronism on the initial starting voltage and without excitation. Under these conditions the maximum load the $200-\mathrm{kv}-\mathrm{a}$. motor would carry is $70 \mathrm{kw}$. Obviously, larger loads can be pulled into synchronism by exciting the motor before synchronism is attained and depending upon the excitation to pull the motor into synchronism. Unfortunately, tests under these conditions could not be made with the same motor that was used for the previous oscillograph tests. The two motors, however, are of such similar design that the loads carried, considered as a percentage of the motor normal rating, may be fairly compared. The $70 \mathrm{kw}$. carried by the $200-\mathrm{kv}-\mathrm{a}$. motor without excitation represents 35 per cent of the normal rated torque of the motor. The $150-\mathrm{kv}-\mathrm{a}$. motor synchronized a load of $90 \mathrm{kw}$., or 60 per cent of its normal rating with maximum excitation. The load was obtained by belting a direct current generator to the synchronous motor and loading the generator on resistance. The load varies approximately with the square of the speed (with constant resistance), the loads referred to being the maximum load at synchronous speed. This condition is illustrated in Fig. 27. The oscillogram clearly shows how the phase position of the rotor with respect to the armature current and flux is changed by the application of field excitation. During the interval that the line switch is open, the motor evidently falls behind with respect to the phase of the line voltage to such an extent that on closing the switch the motor is not in synchronism with consequent abnormal increase in armature current and variation in field current. Under this condition of load, therefore, the same simple relation between instantaneous increase in applied voltage and resulting current, as shown in Fig. 23, does not hold. In Fig. 27 with practically zero instantaneous increase in voltage the maximum current is approximately 200 amperes. In Fig. 29, with 1800 volts increase, the maximum current is only 150 amperes.

V-Motor Running on Partial Voltage with External Load Excited but not in Synchronism; Full Voltage then Applied and Synchronism Attained

Still larger loads can be synchronized if the final voltage is depended on to pull the motor into synchronism. It was found 
PLATE $X X X I X$

A. I. $E$ E.

VOL. $X X X I I$, NO 6

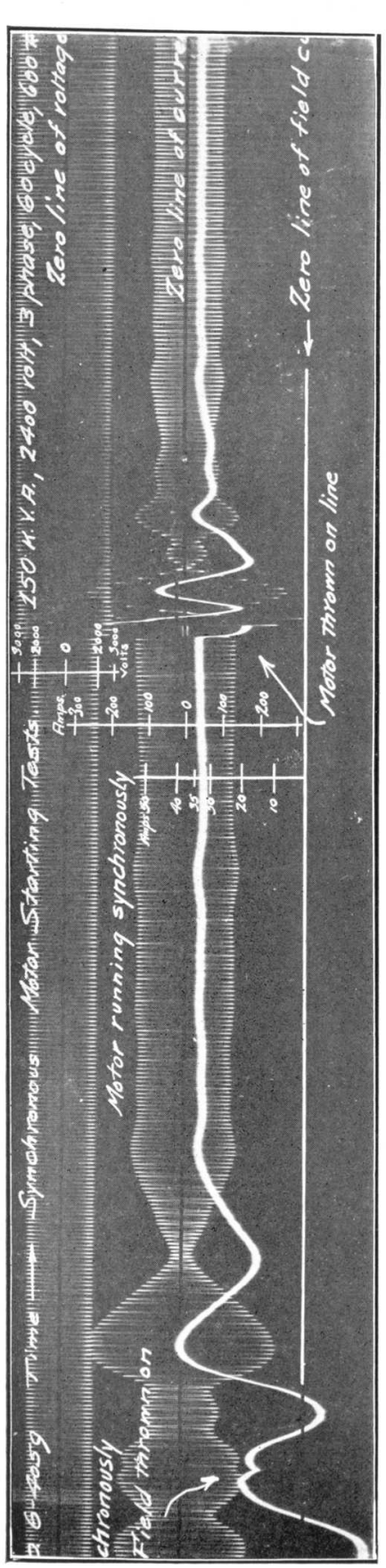

空

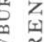

要

要,

空

年

된

离

20

i

욍

5

$>$

品

중

的苗

Nल

安

茫

II

象

U

i 0

z

穿

⿶

도

독

zin

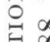

tis

U

究

荘

ž

空

복

z

ษ

r

is

(2) $\overline{5}$

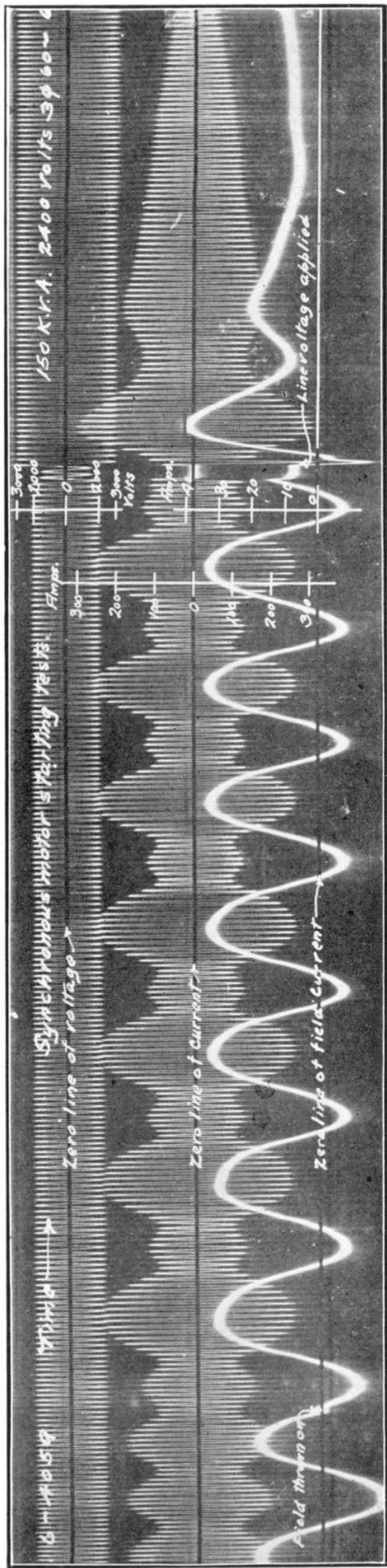

党

学

定

空

空

里

현

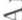

20

เ

엉 중

芺

음

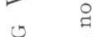

$3 \simeq$

$\approx$ 언

is 2 정

NN100 $<$ <

$\rightarrow 7$

ن

$+20$

0 )

$>$ 'ू。

異在草

고응

동 궁

石

을

요

品

茫

$<\quad$

z

- d

푀 콜

学 落

\%

II

os

is

^

궁

泉

की

空 

PLATE XL

A. I. E. E.

VOL. $X X X I I$, NO. 6

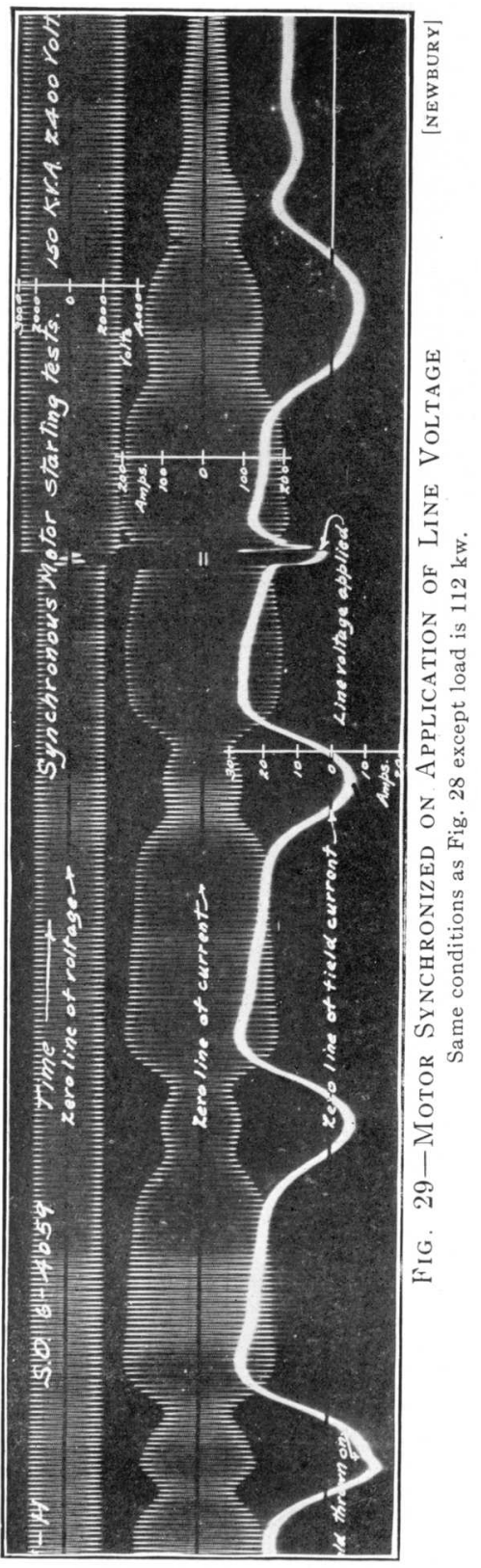



PLATE XLI

A. I. E. E.

VOL. $X X X I 1$, NO. 6

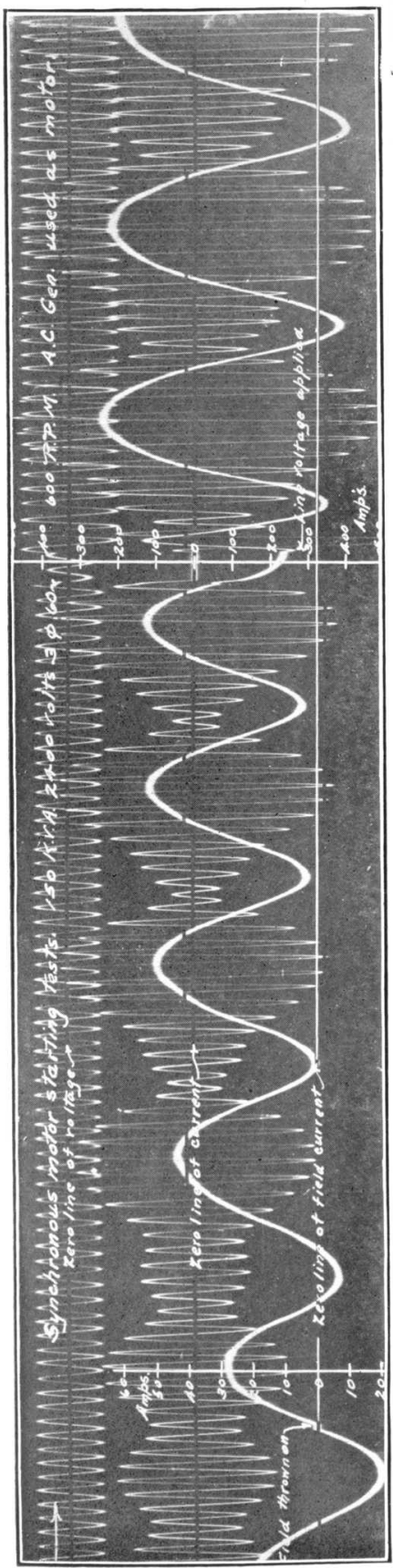

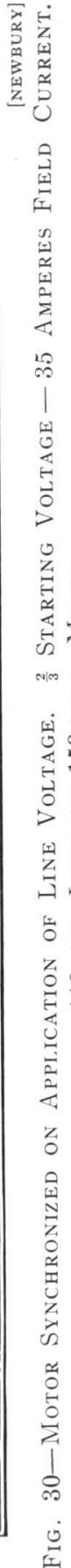

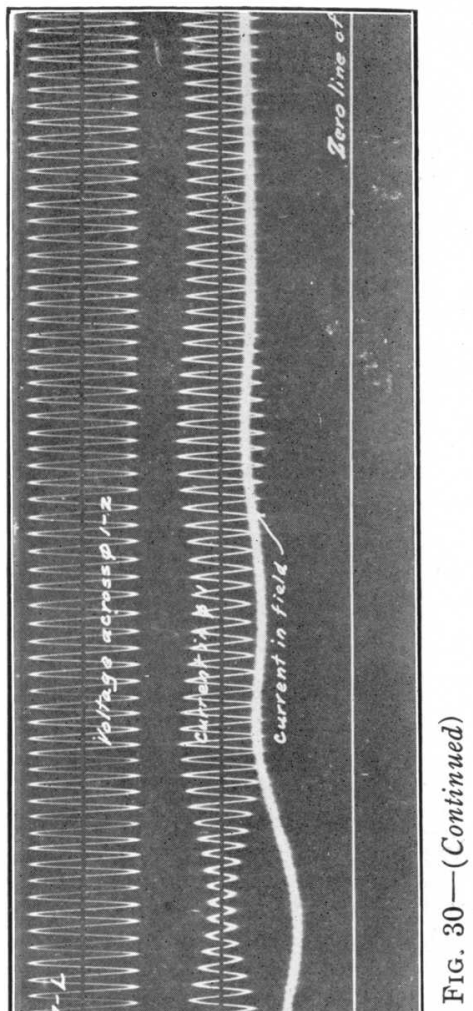

03

음ㅇ

근

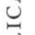

a

z

된

学

II

Z

응

$\frac{5}{5}$

0

$\underset{1}{0}$

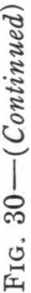



by experiment that a load of $139 \mathrm{kw}$. could be synchronized in this manner. This load is equal to 92 per cent of the motor rating. On successive trials, loads of $139 \mathrm{kw} ., 133 \mathrm{kw}$. and 123 kw. were synchronized. Further increase in the load was limited by the assumed heating limit of the motor windings. The tested loads, therefore, do not represent the maximum loads that can be synchronized without regard to other limits. These results were obtained with a field current of 15 amperes which is somewhat less than the current required for normal voltage on open circuit. Oscillograms illustrating this condition are shown in Figs. 28 and 29. All conditions in the two oscillograms are the same except the loads carried by the motor. In Fig. 28, the load is $112 \mathrm{kw}$., and in Fig. 29, $139 \mathrm{kw}$. In both oscillograms it will be noticed that during the time the motor is excited on low voltage, and is not in synchronism, the maximum armature current on each successive swing is slightly greater. This indicates that the condition is unstable and if continued long enough the motor will swing far enough from its proper phase position to lose its torque and stop.

In Fig. 30 is shown an oscillogram for the same conditions except that the excitation is increased to 35 amperes, the field current resulting from 125 volts on the field without the rheostat. The load at synchronous speed is $110 \mathrm{kw}$. Comparing Fig. 30 with Figs. 28 and 29 , it will be noted that the increased excitation is detrimental. The armature current when the field is excited is much larger and the current increases more on successive swings. The armature current and field current are greatly increased on increase in voltage to normal, and it requires a longer time (six complete oscillations instead of three) for the rotor to drop into exact synchronism.

The probable reason for the better performance with underexcitation is the more advantageous initial position of the rotor (with respect to the line voltage). With under-excitation the rotor is ahead of the field due to the line voltage and with overexcitation the rotor is behind. Consequently, when the line voltage is removed and the rotor drops back due to the braking action of the load, it is not so far out of phase with under-excitation as with over-excitation. This explanation can only apply when the rotor is in synchronism on the low voltage as in Fig. 27. When the motor is not in synchronism on the low voltage, the phase position at the instant of change in voltage is not determined by the excitation, but by chance. 
The complete statement of the effect of excitation on armature current when line voltage is applied, therefore, becomes:

With motor loads such that the motor is in synchronism before the application of line voltage and does not greatly fall back during the interval the line switch is open, the maximum current is proportional to the instantaneous increase in voltage and overexcitation is the most favorable condition. When, however, the motor is heavily loaded so that the motor is not in synchronism before the application of line voltage or does greatly fall back during the interval the line switch is open, the maximum current depends on the extent to which the rotor is out of phase at the instant of line voltage application, and under-excitation is generally the most favorable condition.

In practise the motor is usually in synchronism on the starting voltage so that in the majority of cases over-excitation is the best condition.

It will be noted from the oscillograms that these large loads have been started and synchronized at the expense of excessive line currents. The maximum current amounts to 6.5 times the rated current of the motor with under-excitation and to 9 times with over-excitation. This large current is not objectionable, providing the motor rating is small compared with the generator capacity supplying it, and providing the motor winding and starting equipment have been designed with these large currents in view. It should also be borne in mind that the motor tested was not designed specifically for this service. This value of starting current could be materially reduced by modification of the design of the motor of approach more closely the usual design of an induction motor and by the use of reactance in the starting circuit. It will be noted that if the starting current is reduced by the insertion of reactance as an intermediate step between starting and line voltage, it will be necessary to reduce the current rush on application of excitation, if any material reduction in current is to be obtained, as the latter current is nearly as large as the current rush on application of line voltage. This, obviously, can be done by delaying excitation until the motor is running in synchronism on line voltage. While this method of starting and synchronizing was not tried with the $150-\mathrm{kv}$-a. motor used for the oscillograms shown, it has been tried with other motors and found successful. With a 200-kv-a. 6600-volt, 25-cycle 500-rev. per min. motor designed to drive a mine fan, the fan load amounting to 200 h.p. (represented on 
test by a loaded d-c. generator) was started and synchronized with a maximum line current (measured. by oscillograph) equal to 2.44 times the rated current of the motor. Without the reactance the current rush on changing from the starting voltage of 5000 volts to line voltage of 6600 was sufficient to trip the circuit breakers. While the current was not measured the reactance clearly caused a large reduction in current.

The main facts in regard to synchronous motor starting as discussed in this paper form only a small part of the story that the oscillograms might tell, as the result of a complete and detailed analysis. The study the author has been able to give them has been, to the author, both interesting and profitable and. independent study by other engineers will, it is felt, be well worth while. 